\section{Stellungnahme zum Leserbrief von Dr. A. Wienke}

$\mathrm{S}$ elbstverständlich war und ist es nicht Intention meines Artikels zum Thema „Neufassung der Hilfsmittel-Richtlinie“ irgendeine Rechtsposition zu vertreten; auch nicht in der Frage, ob im Falle von Folgeversorgungen im Rahmen der vertragsärztlichen Versorgung eine ärztliche Verordnung vorliegen muss. Vielmehr war es Ziel meines Beitrags, die Neufassung der Hilfsmittel-Richtlinie inhaltlich darzustellen und - wo nötig - aus audiologischer Sicht zu kommentieren.

Dabei ist mir allerdings ein Lapsus unterlaufen, indem ich mich auf die Fassung der „Tragenden Gründe zum Beschluss“ bezogen habe, die zum Zeitpunkt der Abfassung meines Artikels aktuell war (http://www.g-ba.de/downloads/40-268-1832/2011-12-21_ HilfsM-RL_Neufassung-Hoerhilfen_TrG.pdf). Dort hieß es im Wortlaut: „\$2 27 sieht in Absatz 1 nunmehr vor, dass die Abgabe von Hörhilfen zu Lasten der gesetzlichen Krankenversicherung nur auf der Grundlage einer vertragsärztlichen Verordnung erfolgen darf. Dies gilt nicht für Folgeverordnungen. ..." Zum Zeitpunkt der Drucklegung waren die „Tragenden Gründe zum Beschluss“ allerdings überarbeitet worden und der Satz „Dies gilt nicht für Folgeverordnungen " war entfallen (http://www.g-ba.de/ downloads/40-268-1897/2012-03-15_HilfsM-RL_NeufassungHoerhilfen_TrG.pdf). Diese Änderung ist mir beim Korrekturlesen meines Artikels leider entgangen.

Wie Herr RA Dr. Wienke in seinem Leserbrief ausführt, existiert zu der von ihm vertretenen Rechtsauffassung in diesem Punkt eine Gegenposition. Diese stützt sich auf rechtliche Bedenken des Bundesministeriums für Gesundheit (BMG), die das Ministerium im Rahmen seiner Rechtsaufsicht in einem Schreiben an den G-BA geäußert und begründet hat (http:// www.g-ba.de/downloads/40-268-1886/2011-12-21_HilfsMRL_Neufassung-Hoerhilfen_BMG.pdf). Ob diesen Bedenken in der aktuellen Fassung der „Tragenden Gründe zum Beschluss" adäquat Rechnung getragen wird und die jetzigen Formulierungen damit Bestand haben, ob rechtliche Schritte zur weiteren Klärung ergriffen werden und zu welchem Ergebnis die juristische Auseinandersetzung um die Neufassung der Hilfsmittel-Richtlinie letztlich führen mag, bleibt abzuwarten. Wie auch immer: ich sehe dem Resultat dieses Klärungsprozesses in aller Neutralität und mit großem Interesse entgegen.

Vielleicht heißt es am Ende ja tatsächlich: „Keine Hörgeräteversorgung ohne HNO-Arzt".

\section{Prof. Dr. Jürgen Kießling}

Funktionsbereich Audiologie

HNO-Klinik der Universitätsklinik Gießen und Marburg

Standort Gießen

Klinikstraße 33

35392 Gießen

E-Mail: juergen.kiessling@hno.med.uni-giessen.de
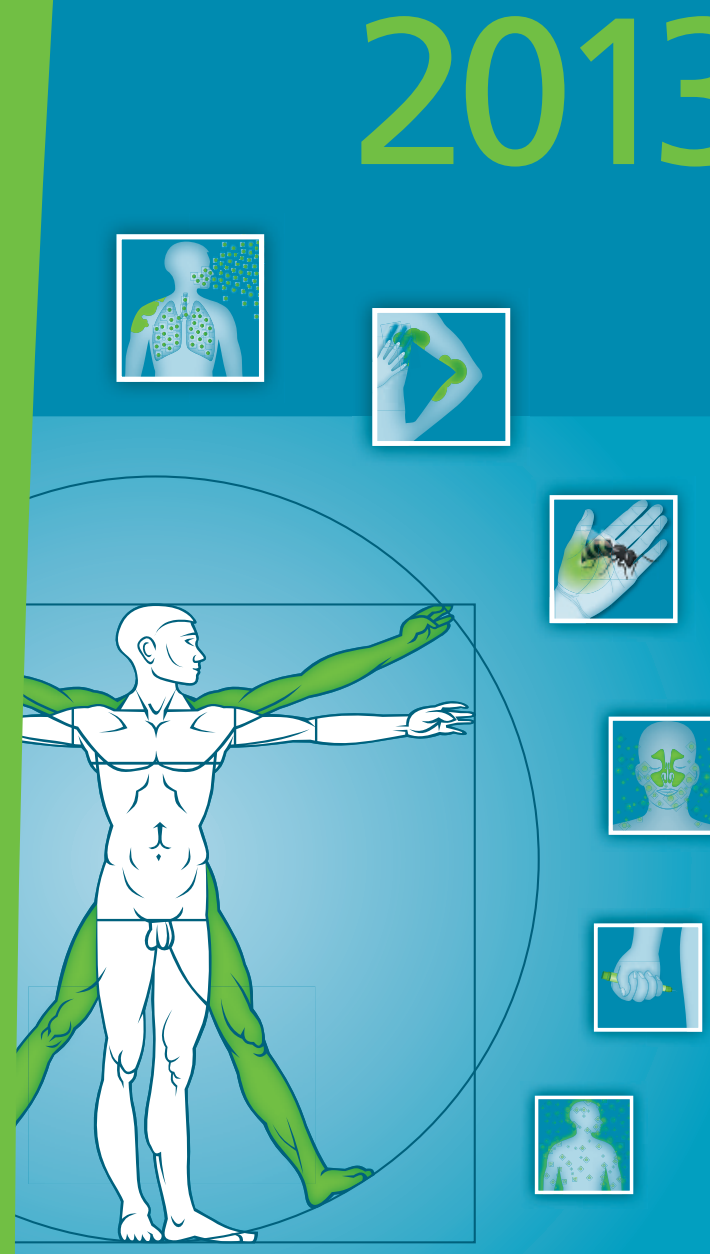

3. Allergologie-Update-Seminar

22. und 23. Februar 2013, Wuppertal

Wissenschaftliche Leitung

Ulrich Wahn, Berlin

Claus Bachert, Gent

Christiane Bayerl, Wiesbaden

Ludger Klimek, Wiesbaden

Harald Renz, Marburg

Thomas Werfel, Hannover

Anmeldung und weitere Informationen unter

www.allergo-update.com 